\title{
Performance evaluation of discrete manufacturing workshop
}

\author{
Chong-Yu Su ${ }^{1, a}$, Yu-Duo Wang ${ }^{1, \mathrm{~b}}$ and Xiao-Dong You ${ }^{2, \mathrm{a}}$ \\ ${ }^{1}$ Beijing Information Science and Technology University \\ ${ }^{2}$ The first research institute of the ministry of public security \\ a 124005904@qq.com, b14694274@qq.com
}

Keywords: Discrete Manufacturing Workshop, performance evaluation, The Balanced Score Card, The Key Performance Indicators.

\begin{abstract}
With the improvement of manufacturing level, competition is becoming more and more serious. How to improve our core competitiveness and improve our performance management ability becomes a key problem in manufacturing enterprises. In order to evaluate the performance of discrete manufacturing workshops scientifically and effectively, this paper analyses the ecosystem of discrete manufacturing workshops and constructs the ecological model of discrete manufacturing workshops. Aiming at this model, the paper presents the characteristics of two performance evaluation methods: The Balanced Score Card and The Key Performance Indicators. And in the end, the paper concludes the method of performance evaluation of discrete manufacturing workshop.
\end{abstract}

\section{Introduction}

At present, the international manufacturing industry develops rapidly, and the advantages of cheap labour as a manufacturing enterprise in China are gradually disappearing. The discrete manufacturing plant is the most basic core part of manufacturing enterprises, and how to improve production efficiency and end the extensive production of the past, became the top priority of managers. Under the background of new markets, how to strengthen the performance management ability of discrete manufacturing workshop in the face of many challenges, it is extremely important to break the development limitation.

Performance evaluation is a very important part of performance management, it has a lot of kinds, but each kind of performance evaluation method has its own characteristics, in the face of complicated application scenario, it is impossible to do as good as it gets. The traditional performance evaluation method often evaluates the single index, and the problem of enterprise development cannot be clearly presented to the manager. In addition, the performance evaluation of the enterprise sector is very few. It is necessary to put forward a set of feasible performance evaluation model for the discrete manufacturing workshop as the core part of manufacturing enterprises.

This paper mainly explains the concept of the discrete manufacturing workshop system, constructs the ecological model of the discrete manufacturing workshop, analyses the two kinds of performance evaluation methods that are popular, and clarifies their characteristics clearly. Finally, the performance evaluation method of discrete manufacturing workshop is summarized.

\section{Discrete manufacturing workshop system}

\subsection{The concept of discrete manufacturing workshop system}

The system is an organic whole that is connected to each other, with different kinds of elements'. The system includes structure, function, process, and environment. These four sections explain' what it is',' to do what ', 'how to do' and 'what is the condition'. The discrete manufacturing plant system, which is an organic mix of people, machines, materials, and capital, and has a series of interactions, which ultimately give the raw material more value, and thus the process of profit.

There are many ways of classifying the workshop. For example, classification of value 
attributes, including assignment process and non-assignment process; Classification by importance, including core process, auxiliary process, etc.; From functional perspective, including production process, management process, etc. Among them, the discrete manufacturing workshop is a kind of workshop according to the production process.

The study of discrete manufacturing workshops is one-sided in terms of equipment and technology. The enterprise ecosystem is to understand the enterprise as part of the ecosystem, and directly or indirectly interact with other enterprises or organizations to achieve the goal of coconstruction. Discrete manufacturing plants as part of the enterprise, it should consider more various factors, the discrete manufacturing plant as a part of the enterprise ecosystem , it should as much as possible into contact with other external factors, the maximum play to the utility of discrete manufacturing plant. The following will analyse the system ecology of the discrete manufacturing workshop from four parts: finance, production, customers and personnel.

\subsection{The ecological model of the discrete manufacturing workshop system}

The system is part of the ecosystem, research the ecosystem which has a vital role in improving systems efficiency, strengthening the system's profit output. The ecological model of the discrete manufacturing workshop system can be composed of: financial dimension, production dimension, customer dimension and personnel dimension, and its model is shown in figure 1.

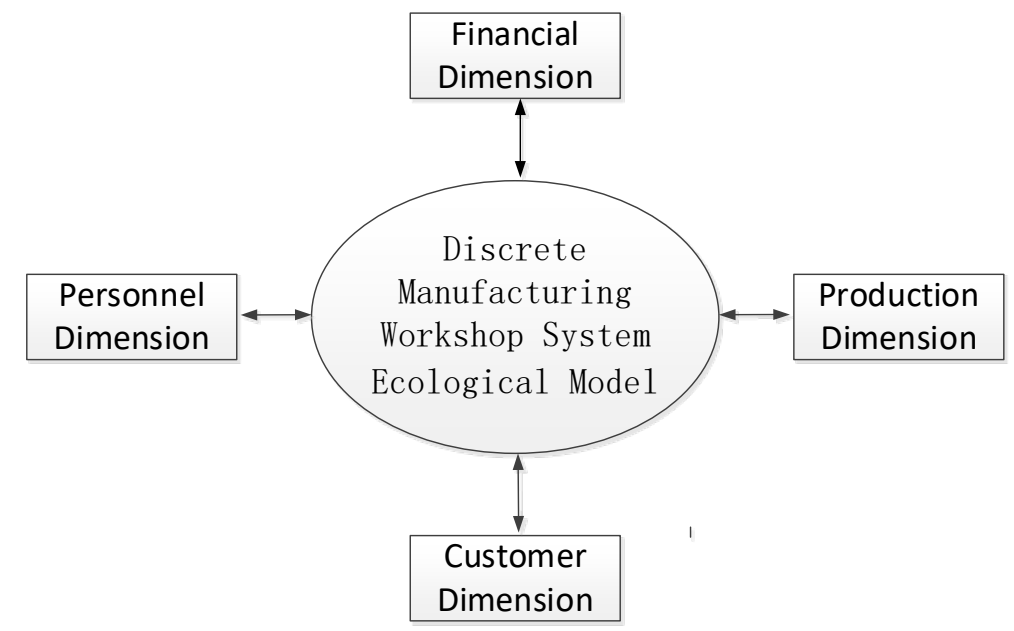

Figure 1 ecological model of discrete manufacturing workshop

\subsubsection{The financial dimension}

Capital is the blood of manufacturing enterprises, from the purchase of raw materials and the consumption of energy consumption to the waste product rate of the products, all of which reflect the flow of funds in the whole production process. For discrete manufacturing enterprises, the cost of manufacturing directly affects the profit and core competitiveness of enterprises. Good financial status is the necessity of sustainable development of the production performance, through financial position feedback, managers can more clearly see capital gains weak efficiency, thus more reasonable resource integration and allocation.

\subsubsection{The production dimension}

The production and manufacturing is the soul of the discrete manufacturing enterprise, how to produce the products with good quality and low price is the primary concern of the production managers. In the production dimension, there are many factors that affect the product, and enterprises also hope that the manufacturing process can be continuously improved to eliminate the disadvantages of the production process. Therefore, the management of production dimension should be the most important part of the system management of discrete manufacturing workshop. 


\subsubsection{The customer dimension}

As the final destination of the product, the customer's demand and opinion are the bellwether of future product trend. With the continuous improvement of customer requirements, product quality, price, delivery speed, after-sales service and other factors become the key to the product is competitive. Therefore, it is very important to keep track record of customer status information.

\subsubsection{The personnel dimension}

The production process can't be lack of the participation of workers, workers technical level of high and low, the strength of the security responsibility consciousness, and even corporate culture impact on workers' mentality in the subtle influence the quality of the products. Therefore, the assessment of the skill level of workers and the flow of talents should also attract the attention of managers.

\section{Performance evaluation method}

Performance is the case where an organization or individual is determining the cost and cost of investment in time. However, in this process, some key factors will have a significant impact on the results, so the managers should effectively control these factors and optimize these factors to achieve the goal of improving the performance of enterprises and make greater profits for enterprises.

Traditional evaluation methods and indicators are static, single and passive, which can not adapt to the long-term sustainable development of enterprises. Specifically, the traditional evaluation method mainly has the following problems:

(1) Ignore the role of non-financial indicators in performance evaluation;

(2) Focusing too much on short-term benefits, thus neglecting the sustainable development strategy of enterprises;

(3) Pay attention to evaluation results and ignore evaluation process.

Therefore, a number of new performance evaluation methods emerged, including the most widely used including BSC and key performance indicators (KPI).

\subsection{Balanced scorecard}

BSC (The Balanced Score Card, or BSC) was born in the 1990 s, after 20 years of continuous practice and improvement, The Balanced scorecard has been gradually by the performance management tool into a systematic theory of strategic management. BSC is a financial information as a basis, balance the short-term and long-term, internal and external, because before to such factors as the consequence, combined with the enterprise strategic target and business performance through the financial dimension, the customer dimension, the internal business process dimension and the learning and growing dimension, form close performance measurement index system, to achieve a variety of balance. The model of the balanced scorecard is shown in figure 2.

\subsubsection{The financial dimension}

Financial indicators are the core of traditional performance evaluation and the main focus of enterprises. Therefore, BSC retains the financial dimension as one of the performance indicators. The performance indicators of the financial dimension provide the most intuitive result information for the process scheme that has been implemented, the profit and loss situation is clear, and it is the best way to judge the feasibility of the process plan from a macro perspective. Financial dimension of index design mostly related to enterprise's profit ability, such as the cost of yield, growth rate, etc. When enterprise design performance evaluation index, profit rate and productivity are generally the core of index design. 


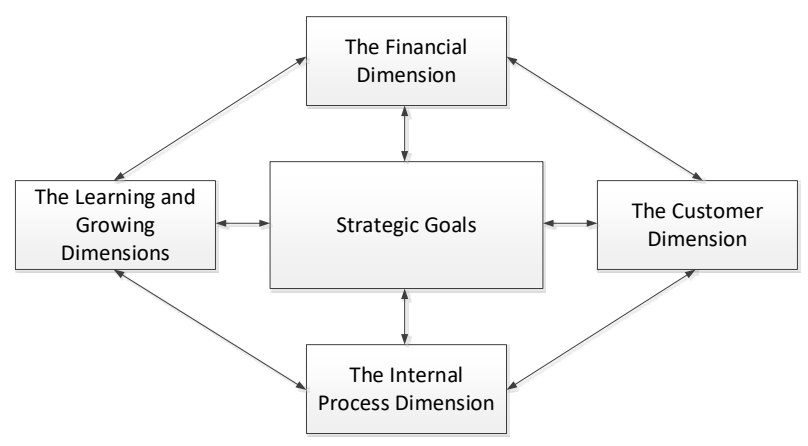

Figure 2 BSC model

\subsubsection{The customer dimension}

The core part of the customer dimension evaluation index is to clarify the competitive market and acquire target customers. In the customer dimension, the market positioning of products can be determined from the side to determine the competitive advantage. While attracting more customers, maintaining the quality of existing customers enables enterprises to continuously have a high quality customer base. Its core evaluation index includes market share, customer benefit rate and so on. These indicators are tightly connected and can form a causal chain.

\subsubsection{The internal business process dimensions}

Internal business processes based on customer demand as the starting point, the basis of market environment, the enterprise through the input factors of production, to provide customers with a series of valuable products or services, in order to achieve profitable purpose core link. Improving the efficiency of internal business processes and maximizing the utilization rate of enterprise resources is the key point of enterprise development. In the production department of manufacturing enterprises, the internal business processes are mainly aimed at the development, equipment, process, staff, products and so on, in order to establish their own evaluation indexes.

\subsubsection{The learning and growing dimensions}

The establishment of learning and growing dimensions is based on the following understanding: Enterprise in order to achieve long-term sustainable development, get rid of the present situation of the "long tail", it is necessary to constantly learn and improve, keep in the current technical level and management situation is impossible of competitiveness. The evaluation indexes of learning and growing are mainly aimed at the following aspects: assessment of employee skills, employee satisfaction, employee turnover rate, labour productivity and so on.

Compared with the traditional performance evaluation system, BSC is more in line with the factors of diversity and comprehensive performance evaluation system setting principle. In addition, it gives a complete set of realistic operable indicator frame system. BSC combines both financial and non-financial indicators to further demonstrate the business conditions of the enterprise. First of all, the evaluation index can be combined with the process factors from the financial perspective to clearly reveal the omission of the company's sustainable development strategy in the implementation process, and find loopholes and avoid losses in time. Secondly, BSC can avoid short-term behaviour of enterprises. If only financial evaluation indexes are adopted, the potential of long-term future of enterprises cannot be evaluated based on the information of the enterprise in the past. The diversity index used by BSC can help enterprises find the key factors of sustainable development, so that enterprises can formulate long-term strategic objectives with feasibility according to the actual situation.

\subsection{Key performance indicators (KPI)}

KPI (Key performance indicators) is a method of performance evaluation through design Indicators and quantitative results. By breaking down strategic objectives, enterprises can achieve 
small targets that are easy to achieve and improve their efficiency. At present, the key performance evaluation index is a popular word in human resources management, its role is to make staff work more has the focus and direction, thus greatly improve enterprise's production efficiency and gain more profits. The basic characteristics of KPI are:

(1) KPI can focus on the individual work contribution of the team, the value of individual creation;

(2) KPI can define the scope of key outputs and establish the weight of production.

(3) KPI can track individual performance so as to get personal work defects and help employees improve through comparative analysis of actual performance and index standards.

The establishment principle of KPI method is the principle of "28 principle". According to this principle, the most important influencing factors should be selected according to the actual situation when formulating the assessment indicators, and as the evaluation index, the evaluation index can be used to restrain the behaviour of employees while allowing employees to play their best. Moreover, the less assessment indicators can effectively improve the efficiency of performance management, greatly reduce the management expenditure and enhance the core competitiveness of enterprises.

KPI do not have a framework to apply when designing key performance indicators, but they have to follow the principle of SMART in the design process. "SMART" is the first of five Specific English words: "S" means "Specific"; "M" means "Measurable". "A" means "Attainable"; "R" means "Realistic". T means "time-bound", When setting up KPI, pay attention to the goal orientation, from the macro considerations, and strictly control the quality, ensure the quality to guarantee the core competitiveness of the enterprise.

KPI have been developed to this day and have become a common performance evaluation method. Because there are fewer constraints in the process of setting indicators. However, this is one of the key drawbacks of KPI. KPI is a theoretical method of performance evaluation, and it does not give a complete operational framework. Further analysis, KPI only specify the direction of assessment, and no specific methods for assessment are given. This makes KPI less scientific and less rigorous. Through reading the literature, there are several problems in the actual application of KPI: Firstly, KPI do not adequately reflect the employee's main work completion status. Since this method is only statistical key performance, and marginalization of other work value, it will be difficult to show the comprehensive value of employees. Secondly, too much design of KPI index can lead to difficulty in evaluation, thus losing the key index of KPI method. This is also due to the fact that KPI do not have a complete framework; Thirdly, the design of KPI index is not comprehensive; Fourthly, the standards of performance indicators are set too high, which makes the index lack of transcendence.

\section{Summary}

At present, the development of performance evaluation is mainly aimed at groups or enterprises, and the results of research and analysis are relatively few for the specific departments such as discrete manufacturing workshops. This article first from the concept of discrete manufacturing plants and ecological environment, constructing the ecological model of discrete manufacturing shop, out of the past only from the production point of view the limitations of discrete manufacturing plant, in the overall macroscopic dimension associated with discrete manufacturing plant. Secondly, this paper analyses the two different performance evaluation methods of the KPI and BSC, and studies the characteristics and application of the two respectively, and finds that BSC is more suitable for the performance evaluation of the discrete manufacturing workshop than the KPI.

Firstly, the key performance indicators lack certain rigor in the process of implementation, and do not give an operable index framework system in performance evaluation. Secondly, KPI are more applicable to individual performance evaluation. However, the key performance evaluation focuses on the "'key"' words, the evaluation indexes should not be too much, and for the enterprise or department level, the number of evaluation indexes will make the key performance evaluation 
lose its operability, and the later analysis will become extremely difficult. But the balanced scorecard gives the basic index system, through the financial dimension, the customer dimension, internal business process dimension and learning and growing dimension, form a close performance measurement index system, and can be from a macro understanding of the ecological system of the discrete manufacturing shop, more comprehensive and detailed analysis of the performance of discrete manufacturing shop, provides the possibility to further raise revenue.

\section{References}

[1] Di Mascolo M., (1996) Sur I'évaluation de performances etle pilotage de systèmes de production, Mémoired'habilitation à diriger des recherches de l'INPG.

[2] Duri C., Frein Y., Di Mascolo M., (2000) "Performance evaluation and design of base stock systems", European Journal of Operational Research, 127 172-18.

[3] Gomez Fernandez J.F. Crespo Marquez, A. (2009), Framework for implementation of maintenance management in distribution network service providers, Reliability Engineering and System Safety 94 1639-1649.

[4] Simeu-Abazi Z. Sassine C. (2001) Maintenance Integration in Manufacturing Systems evaluation and decision International Journal of Flexible Manufacturing Systems 13(3).

[5] Ahrens T,Chapman CS. Accounting for Flexibility and Efficiency: A Field Study of Management Control Systems in a Restaurant Chain[J].Contemporary Accounting Research,2004,21(2):271-301. 